\title{
Psychosocial risk factors for suicidality in children and adolescents
}

\author{
J. J. Carballo ${ }^{1} \cdot$ C. Llorente ${ }^{1} \cdot$ L. Kehrmann ${ }^{1} \cdot$ I. Flamarique $^{2} \cdot$ A. Zuddas $^{3} \cdot$ D. Purper-Ouakil ${ }^{4} \cdot$ P. J. Hoekstra ${ }^{5}$. \\ D. Coghill $\left.\right|^{6,7,8,9} \cdot$ U. M. E. Schulze ${ }^{10} \cdot$ R. W. Dittmann ${ }^{11}$ - J. K. Buitelaar ${ }^{12} \cdot$ J. Castro-Fornieles ${ }^{2,13,14} \cdot$ K. Lievesley $^{15,16,17}$. \\ Paramala Santosh ${ }^{15,16,17 \text { (D) C. Arango }}{ }^{1}$ on behalf of the STOP Consortium
}

Received: 19 September 2018 / Accepted: 20 December 2018 / Published online: 25 January 2019

(c) The Author(s) 2019

\begin{abstract}
Suicidality in childhood and adolescence is of increasing concern. The aim of this paper was to review the published literature identifying key psychosocial risk factors for suicidality in the paediatric population. A systematic two-step search was carried out following the PRISMA statement guidelines, using the terms 'suicidality, suicide, and self-harm' combined with terms 'infant, child, adolescent' according to the US National Library of Medicine and the National Institutes of Health classification of ages. Forty-four studies were included in the qualitative synthesis. The review identified three main factors that appear to increase the risk of suicidality: psychological factors (depression, anxiety, previous suicide attempt, drug and alcohol use, and other comorbid psychiatric disorders); stressful life events (family problems and peer conflicts); and personality traits (such as neuroticism and impulsivity). The evidence highlights the complexity of suicidality and points towards an interaction of factors contributing to suicidal behaviour. More information is needed to understand the complex relationship between risk factors for suicidality. Prospective studies with adequate sample sizes are needed to investigate these multiple variables of risk concurrently and over time.
\end{abstract}

Keywords Children · Adolescents · Youth · Suicidality · Risk · Resilience · Psychosocial · Web-based · Questionnaire

\section{Introduction}

Suicide is one of the major causes of death worldwide, and approximately one million people commit suicide each year [1]. The incidence of suicide attempts peaks during the midadolescent years, and suicide mortality, which increases with age steadily through the teenage years, is the third leading cause of death in young people between the ages of 10 and 24 [2].

Suicidal acts and behaviours are a matter of great concern for clinicians who deal with paediatric patients with mental health problems. Despite its importance, research on suicidality among children and adolescents has been hampered by the lack of clarity of definition. Beyond suicidal ideation and suicide plans, there are a number of behaviours in

The members of the STOP Consortium are mentioned in acknowledgements.

Paramala Santosh

paramala.1.santosh@kcl.ac.uk

Extended author information available on the last page of the article which there is an intention to die, including suicide attempts, interrupted attempts, aborted attempts, and other suicidal preparatory acts. Suicidal behaviours require, not only the self-injurious act, but also there must be a suicidal intent. By contrast, when individuals engage in self-injurious behaviours for reasons other than ending their lives, this behaviour is termed non-suicidal self-injury. Deliberate self-harm behaviours comprise self-injurious behaviours regardless their intentionality.

The features of suicidality in children and adolescents are different from those occurring in adults [3] and there is a need for tools to identify those young people at higher risk. Depression is a factor strongly associated with suicidality in this population [4], but it is not present in all cases [5], indicating that suicidal behaviour is a result of the interaction of multiple factors. Furthermore, not all depressed children and adolescents develop suicidal ideation or behaviour [6], indicating the importance of, e.g. social and temperamental factors. Predicting which adolescents are likely to repeat their suicidal behaviour would help to establish prevention and intervention strategies for suicidality in children and adolescents. 
Biological, psychological, and social factors contribute to a risk profile in children and adolescents. However, the specific purpose of this paper is to review the literature focusing on psychosocial risk factors and suicidality among children and adolescents.

\section{Methods}

\section{Search strategy}

A systematic two-step search was carried out following the PRISMA statement guidelines [7]. A PubMed search was performed using the following terms: (suicidality, suicide, and self-harm), combined with (infant, child, adolescent) according to the US National Library of Medicine and the National Institutes of Health classification of ages using the filters (humans, clinical trial, randomized controlled trial, English), and limiting the search up to December 2016. This search detected 710 papers. In a second step, the references found in the relevant papers were reviewed, identifying 8 additional publications that had not emerged in the initial search.

\section{Selection criteria}

Three researchers (JJC, CL, LK) independently evaluated the abstracts of the 710 studies (see Fig. 1 for flowchart of the literature review). Definitions of suicidal behaviour have varied over time and sometimes differ between the US and Europe. For this review, we considered suicidality a continuum and we used the broader definition of the term selfharm (which includes both suicidal and non-suicidal selfinjurious behaviour as described at the Introduction section).

Papers were selected when they met the following criteria:

- Original articles published in English language from initial online databases until December 2016.

- Child and adolescent participants (under 18 years of age). In publications that included adults, only those that reported on children or adolescents separately were considered.

- Publications whose main aim was to examine risk factors for suicidal behaviour/ideation or that included psychosocial variables as risk factors.

Papers were excluded as follows:

- Reviews, editorials, letters, meta-analyses, and guidelines were not considered for this review.

- Studies that investigated the benefit of a therapy (pharmacological, psychotherapeutic, or community interven- tion), or only analysed suicidal methods, or evaluated psychometric properties of assessment instruments, were excluded.

As a result of this selection process, 77 full-text articles were further assessed.

\section{Data extraction}

The same three researchers (JJC, CL, and LK) reviewed the selected manuscripts. For each study, the following data were extracted: author names, year of publication, number of subjects, age of subjects, inclusion criteria, methodology, and outcome measures.

\section{Data synthesis and analysis}

Studies were classified according to the type of risk factors assessed (psychological factors, adverse life events, and temperament and character factors) and as to sample recruited (clinical vs non clinical samples). Adjusted results were presented.

\section{Results}

\section{Psychological factors}

Twenty-five of the papers reviewed focused on psychological issues as a key outcome measure, and we summarize them below. Depression, previous suicidal attempts, and substance abuse were embedded within a large proportion of the reviewed literature, so we present the studies grouped accordingly. These 25 studies are listed in Tables 1 and 2 (reporting studies based on clinical and non-clinical samples, separately).

\section{Depression}

Depression is considered a major factor in the aetiology of suicidality in children and adolescents [4, 8-12], and it has been reported in both clinical and non-clinical samples. Major depressive disorder was associated with a fivefold higher risk for suicide attempts, even after controlling for other disorders [4], gender, age, race, and socioeconomic status $[8,13]$. In addition, results from a cross-sectional study conducted by Spann et al. suggest that depressive symptomatology (measured by means of the Beck Depression Inventory) mediate the relationship between hopelessness and suicidal behaviours [9].

Nevertheless, non-depressed adolescents may also report suicidal ideation and/or display suicidal behaviours [5, 14]. 
Fig. 1 Study selection flowchart (using PRISMA guidelines) [7]

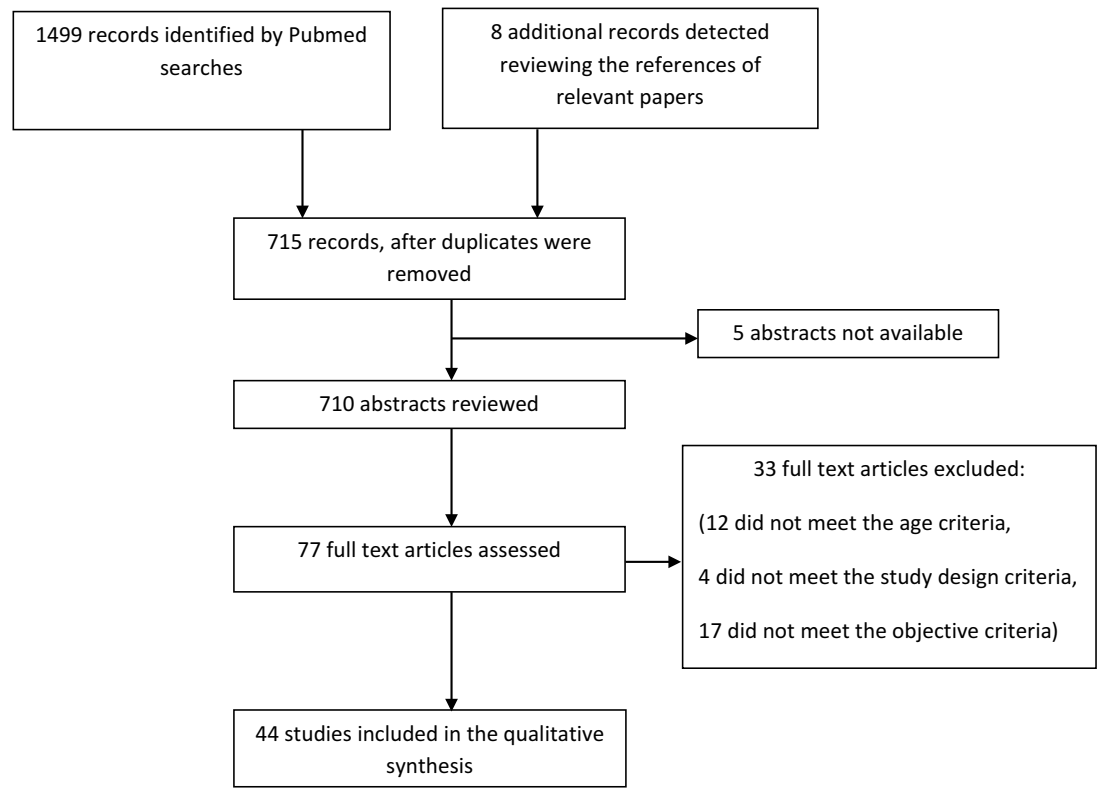

growing interest has focused on the study of suicidal behaviour in autism spectrum disorders [30]. Risk for suicidality seems to be increased as a function of the number of comorbid disorders [4]. In addition, as illustrated in a follow-up study, rehospitalisation appears to be a strong indicator of a future risk of a suicide attempt [31].

\section{Other risk behaviours}

Suicidality in this age range may be associated with low instrumental and social competence, and having been in a fight in which there was punching or kicking in the previous year [8].

\section{Adverse life events}

Serious adverse life events have been reported as preceding some suicides and/or suicide attempts [8, 14, 32]. They are rarely a sufficient cause for suicide/suicide attempts in isolation, and their importance lies in their action as precipitating factors in young people who are at risk by virtue of, e.g. a psychiatric condition and/or of other risk factors for suicidality as detailed below. In this vein, stress-diathesis models proposed that stressful life events interact with vulnerability factors to increase the probability of suicidal behaviour. Nevertheless, stressful life events vary with age. In children and adolescents, life events preceding suicidal behaviour are usually family conflicts, academic stressors (including bullying or exam stress), trauma and other stressful live events. In this review, 11 studies assessed stressors that occur before suicidal behaviour, with similar results for both studies using clinical and non-clinical samples (see Tables 3 and 4). 


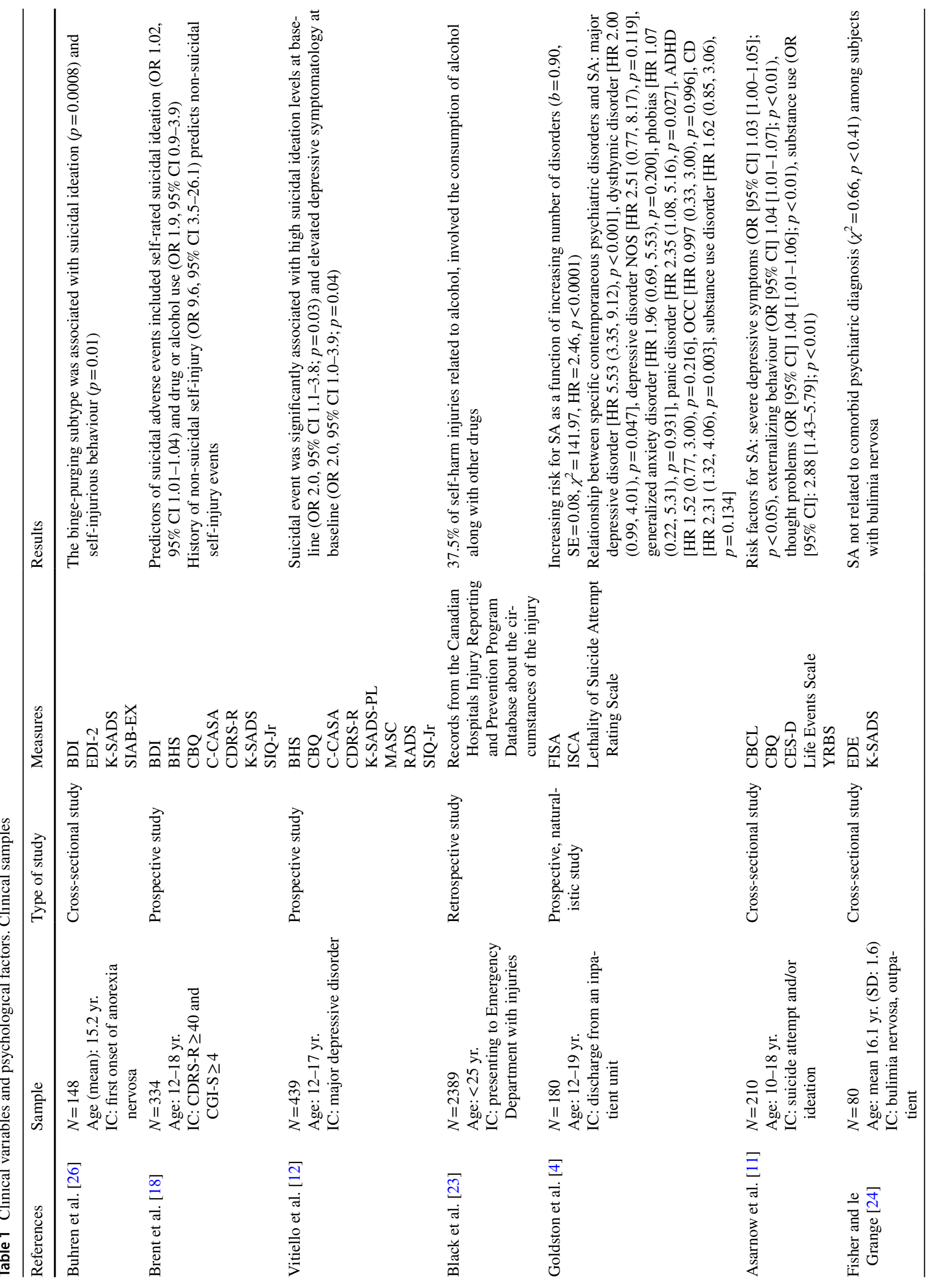




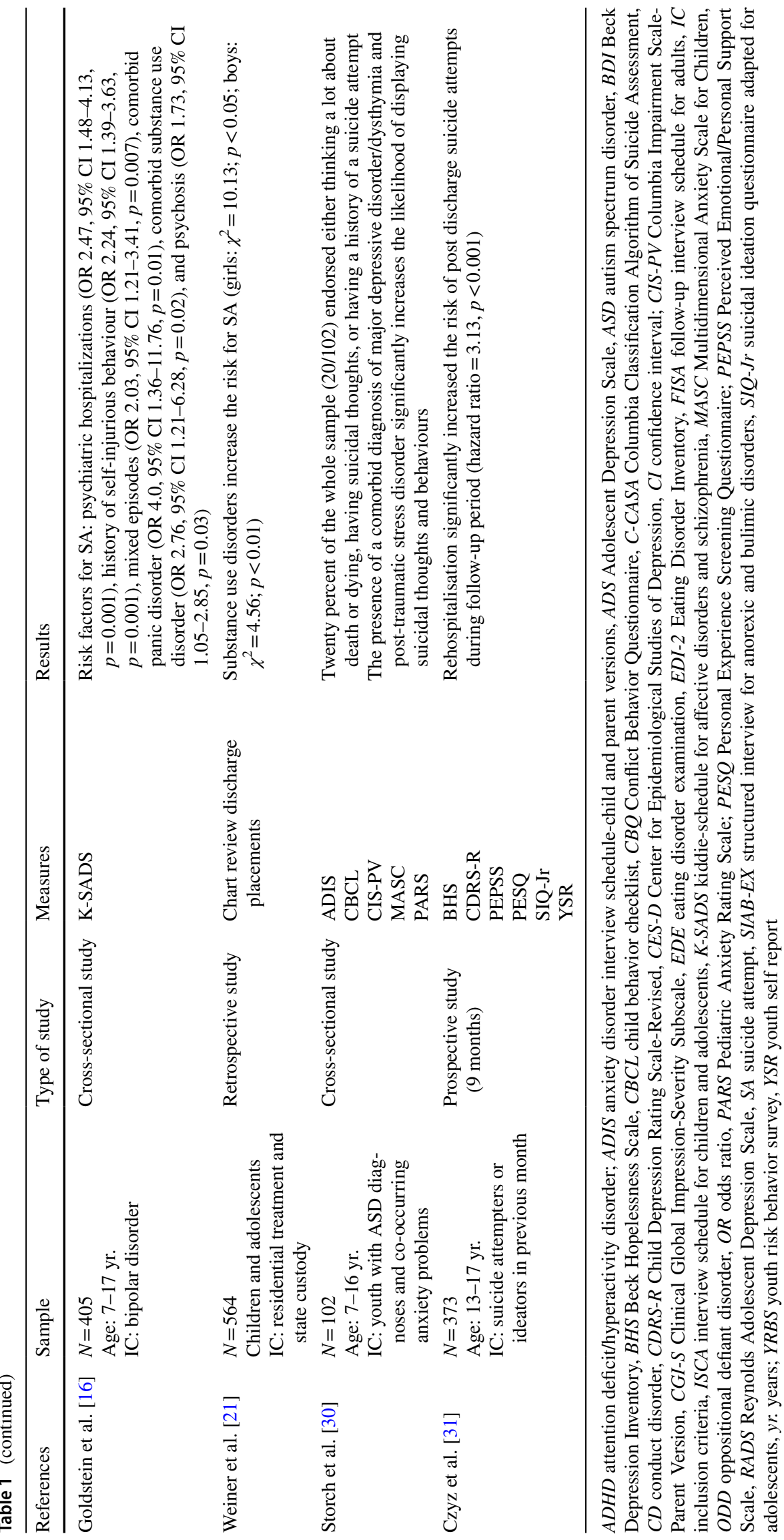




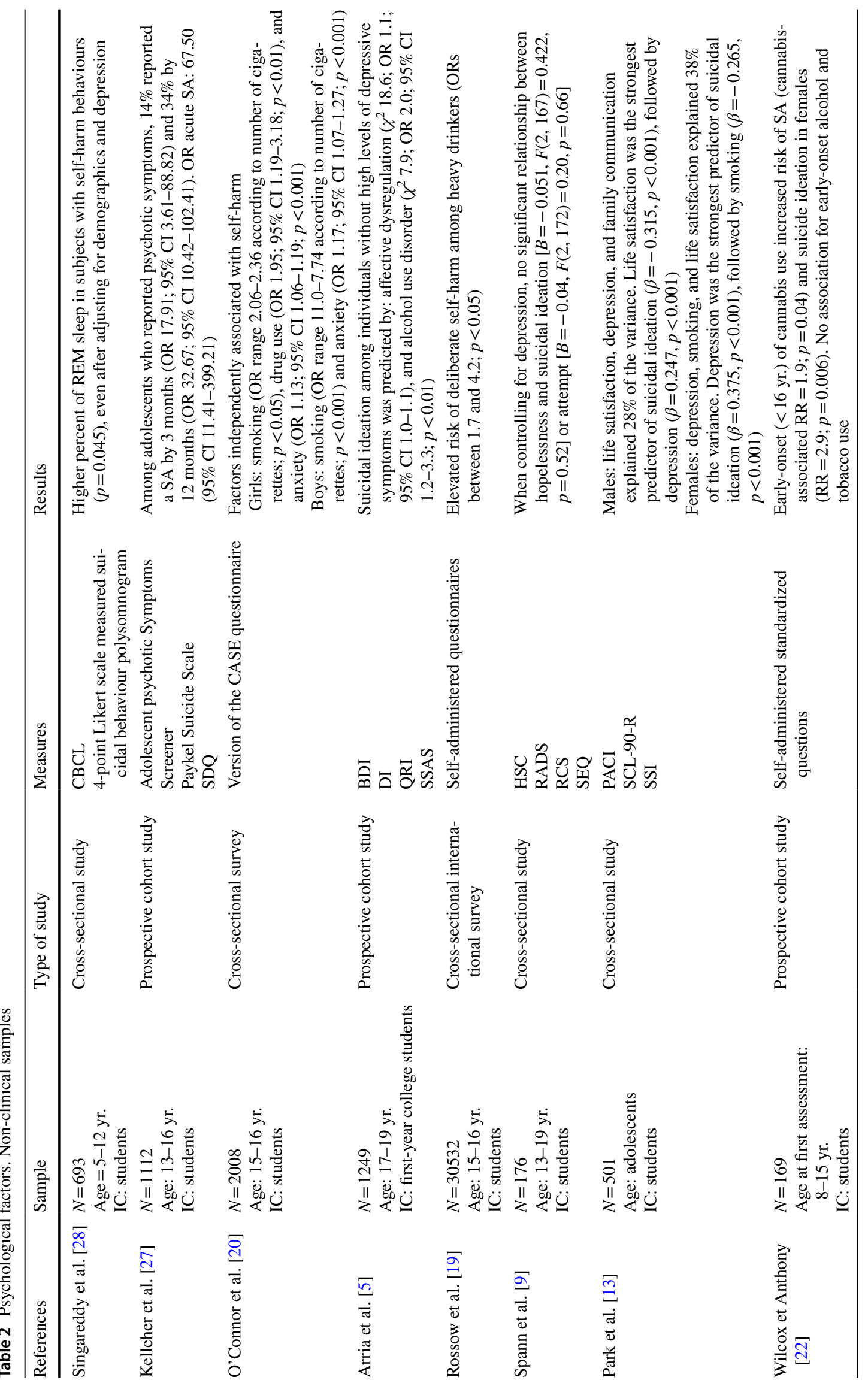




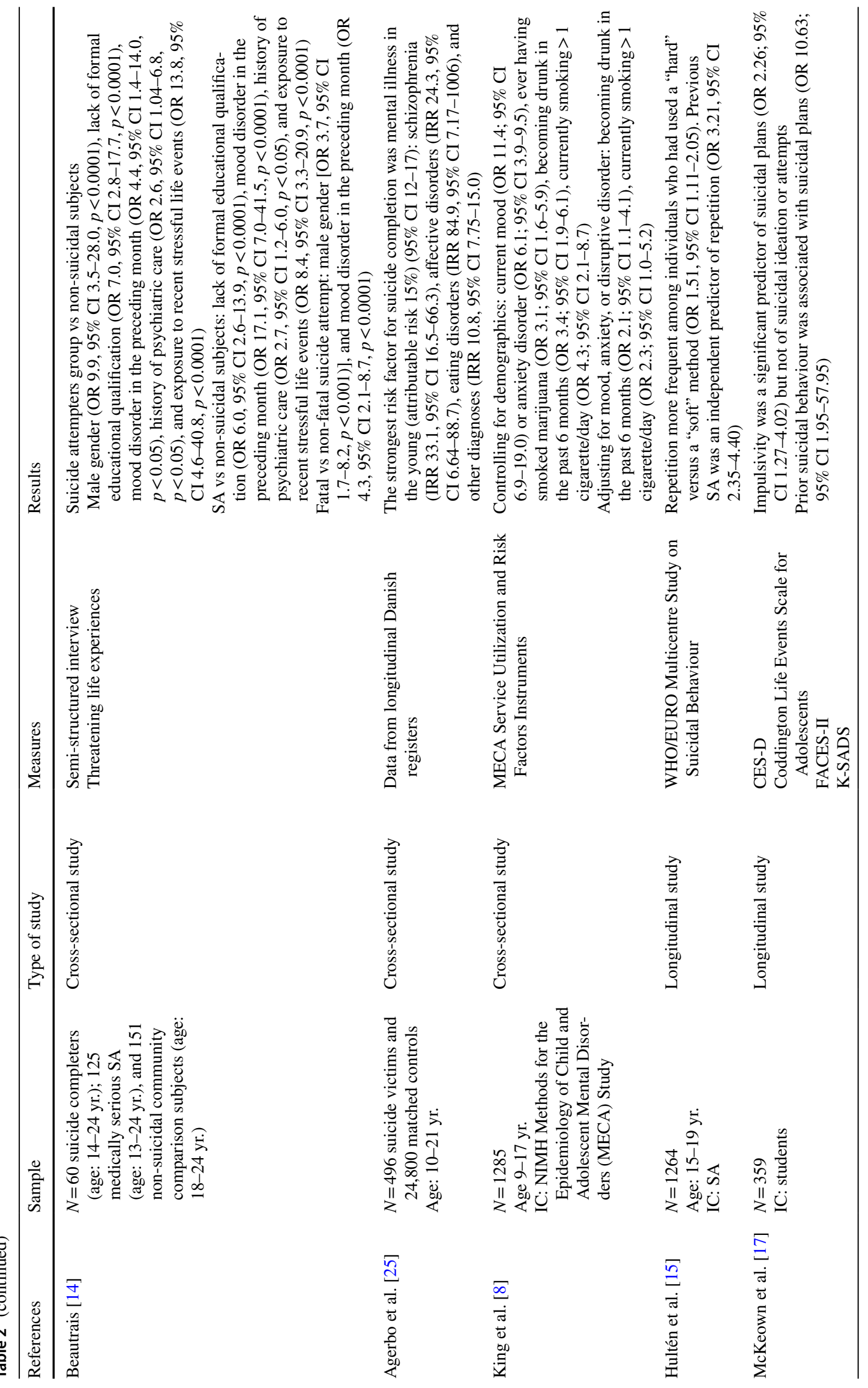




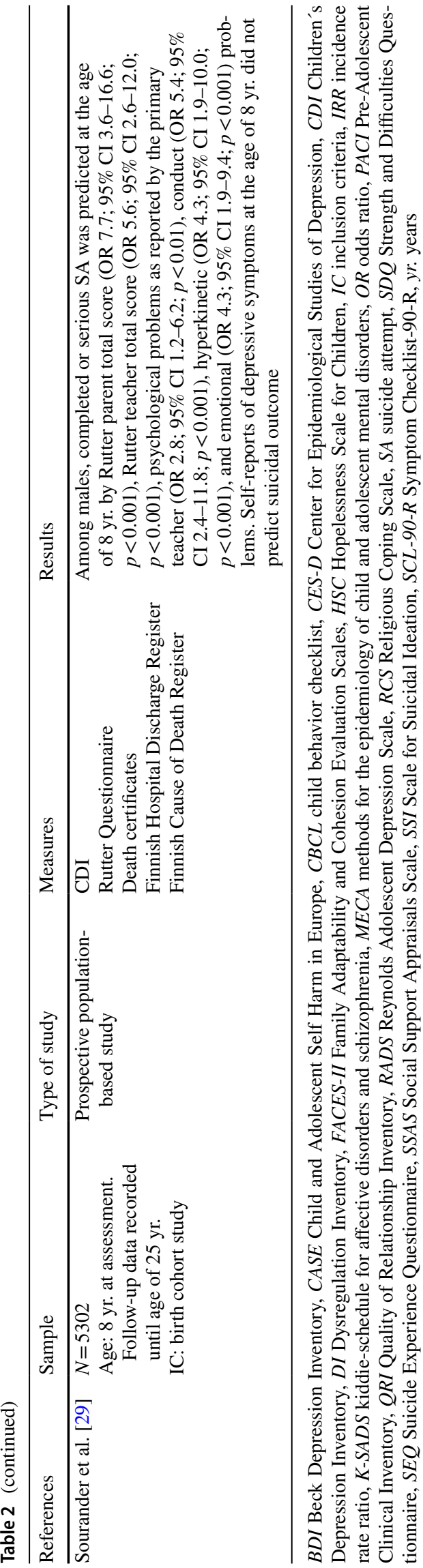

\section{Family conflicts}

Family conflict has been associated with suicidal behaviour [18], even after controlling for gender, age, and psychiatric disorders [8]. Adolescents with a history of a suicide attempt more frequently than controls report stress related to parents, lack of adult support outside of the home, physical harm by a parent, running away from home, and living apart from both parents [33-35]. Other family situations associated with risk for suicidality are: parental suicidal behaviour, early death, mental illness in a relative, unemployment, low income, neglect, parental divorce, other parent loss, and family violence $[20,25,29,36]$.

\section{Academic stressors}

Students who perceive their academic performance as failing seem to be more likely to report suicidal thoughts, plans, threats, and attempts or deliberate self-injury [37]. Perfectionism has been reported as a personality construct that may be associated with suicidality in adult samples. However, results from a pioneering study in children and adolescents evaluating the Perfectionism Social Disconnection Model suggest that the association between perfectionism and suicidality is mediated by stressful life events (being bullied) or by other psychological features such as learned helplessness [38].

\section{Trauma and other adverse life events}

In addition to family conflicts or academic performance problems, early traumatic experiences and other adverse life events have been associated with suicidal behaviours. A history of childhood sexual abuse is associated with a 10.9-fold increase in the odds of a suicide attempt between the ages of 4 and 12 years and a 6.1-fold increase in the odds of an attempt between the ages of 13 and 19 years [36].

Victims of bulling have higher rates of suicidal behaviour and ideation [39, 40], and some victims may be particularly vulnerable to suicidal ideation due to parental psychopathology and feelings of rejection at home [41].

Change of residence may result in loss of a familiar environment as well as a breakdown of the social network, which may induce stress and adjustment problems, and therefore, increase the risk of suicidal behaviour [42].

Other stressful circumstances that may precede suicidal behaviour are peer conflict, legal problems, physical abuse, worries about sexual orientation, romantic breakups, exposure to suicide/suicide attempts, and physical and/or sexual violence among trafficked victims [11, 12, 20, 32, 39, 43-45]. 


\section{Temperament and character}

Some personality traits have been identified as predisposing factors for suicidality. Neuroticism, perfectionism, interpersonal dependency, novelty-seeking, pessimism, low selfesteem, a perception that one is worse off than one's peers, and self-criticism have been implicated as risk factors for suicidality in adolescents [20, 37, 46-49]. Similarly, maladaptive coping styles have been described as a risk factor for both depression and suicidal ideation [50].

Impulsivity has emerged as an important issue in suicidality [17, 20, 51, 52], with $50 \%$ of adolescents having only started thinking about self-harm less than an hour before the act itself [20] (Tables 5, 6).

\section{Discussion}

Suicidality among children and adolescents is a topic of increasing concern, and this is reflected in the strong/large increase in the amount of literature assessing suicidality over recent years. While deaths in these populations due to other causes are decreasing, rates of suicide remain high [2]. This highlights the importance of suicidality research and a move to improving and developing suicide prevention strategies.

This review identifies several psychosocial risk factors for suicidality (Table 7).

The majority of publications reviewed in this present work indicate that young people with suicidal behaviour had significant psychiatric problems, mainly depressive disorders and substance abuse disorders. The presence of a major

Table 3 Adverse life events. Clinical samples

\begin{tabular}{|c|c|c|c|c|}
\hline References & Sample & Type of study & Measures & Results \\
\hline Brent et al. [18] & $\begin{array}{l}N=334 \\
\text { Age: } 12-18 \text { yr. } \\
\text { IC: } C D R S-R \geq 40 \text { and CGI-S } \geq 4\end{array}$ & Prospective study & $\begin{array}{l}\text { BDI } \\
\text { BHS } \\
\text { CBQ } \\
\text { CDRS-R } \\
\text { K-SADS-PL } \\
\text { SIQ-Jr }\end{array}$ & $\begin{array}{l}\text { Family conflict is a predictor of suicidal } \\
\text { adverse event (OR 1.1, 95\% CI } \\
1.03-1.16 \text { ) }\end{array}$ \\
\hline Vitiello et al. [12] & $\begin{array}{l}N=439 \\
\text { Age } 12-17 \text { yr. } \\
\text { IC: Major depressive disorder }\end{array}$ & Prospective study & $\begin{array}{l}\text { ADS } \\
\text { BHS } \\
\text { C-CASA } \\
\text { CDRS-R } \\
\text { K-SADS-PL } \\
\text { MASC } \\
\text { RADS } \\
\text { SIQ-Jr }\end{array}$ & $\begin{array}{l}\text { An acute interpersonal conflict identi- } \\
\text { fied in } 72.7 \% \text { of cases of subjects } \\
\text { with a suicidal adverse event ( } 84 \% \\
\text { youth-parent conflict, } 16 \% \text { youth-peer } \\
\text { conflict). Identifiable recent legal } \\
\text { problem present in } 13 \% \text { of those } \\
\text { subjects with a suicidal adverse event } \\
\text { during follow-up }\end{array}$ \\
\hline Qin et al. [42] & $\begin{array}{l}N=4160 \text { SA; } 79 \text { completed suicides; } \\
2370 \text { matched controls } \\
\text { Age: } 11-17 \text { yr. }\end{array}$ & Prospective study & $\begin{array}{l}\text { Danish } \\
\text { longitudinal } \\
\text { population } \\
\text { registries }\end{array}$ & $\begin{array}{l}\text { Attempted and completed suicide risk } \\
\text { significantly increased with increasing } \\
\text { changes of residence }\end{array}$ \\
\hline Asarnow et al. [11] & $\begin{array}{l}N=210 \\
\text { Age: } 10-18 \text { yr. IC: SA and/or ideation. }\end{array}$ & Cross-sectional study & $\begin{array}{l}\text { CBCL } \\
\text { CBQ } \\
\text { CES-D } \\
\text { YRBS } \\
\text { Life Events Scale }\end{array}$ & $\begin{array}{l}\text { Stressors associated with increased SA } \\
\text { risk } \\
\text { Females: romantic breakups (OR 3.16; } \\
\text { 95\% CI 1.65-6.06; } p<0.001 \text { ) and } \\
\text { exposure to suicide/SA (OR 3.05; 95\% } \\
\text { CI 1.54-6.04; } p<0.001 \text { ) } \\
\text { Males: romantic breakups (OR 5.12: } \\
\text { 95\% CI 1.61-16.24; } p<0.01 \text { ) }\end{array}$ \\
\hline Kerr et al. [34] & $\begin{array}{l}N=220 \\
\text { Age: } 12-18 \text { yr. IC: inpatients }\end{array}$ & Cross-sectional study & $\begin{array}{l}\text { BHS } \\
\text { PEPSS } \\
\text { PESQ } \\
\text { RADS } \\
\text { SIQ-JR } \\
\text { SSB }\end{array}$ & $\begin{array}{l}\text { Suicidal ideation associated with } \\
\text { perceptions of lower family support } \\
\text { among females }(\beta=-0.26, p=0.002 \text {, } \\
\text { and higher peer support among males } \\
(\beta=0.24, p=0.016)\end{array}$ \\
\hline
\end{tabular}

Clinical samples

$A D S$ Adolescent Depression Scale, $B D I$ Beck Depression Inventory, $B H S$ Beck Hopelessness Scale, $C B C L$ child behavior checklist, $C B Q$ Conflict Behavior Questionnaire, $C$-CASA columbia classification algorithm of suicide assessment, $C D R S$ - $R$ Child Depression Rating Scale-Revised, CES-D Center for Epidemiological Studies of Depression, CGI-S Clinical Global Impression-Severity Subscale, $C I$ confidence interval, IC inclusion criteria, $K$-SADS kiddie-schedule for affective disorders and schizophrenia, MASC Multidimensional Anxiety Scale for Children, $O R$ odds ratio, PEPSS Perceived Emotional/Personal Support Scale, PESQ Personal Experience Screening Questionnaire, RADS Reynolds Adolescent Depression Scale, SA suicide attempt, SIQ-Jr Suicidal Ideation Questionnaire adapted for adolescents, SSB Spectrum of Suicide Behavior Scale, $y r$. years, YRBS youth risk behavior survey 


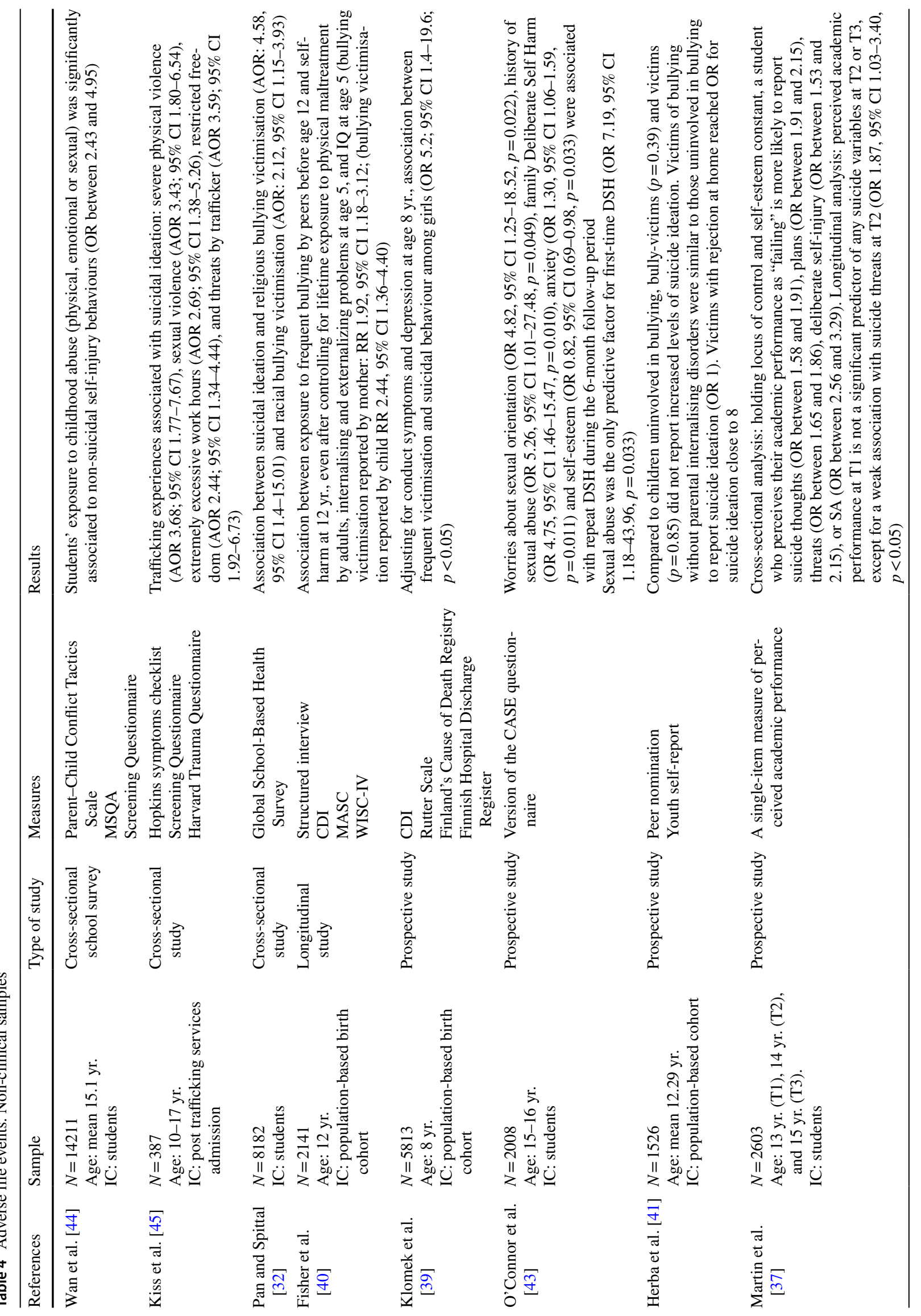




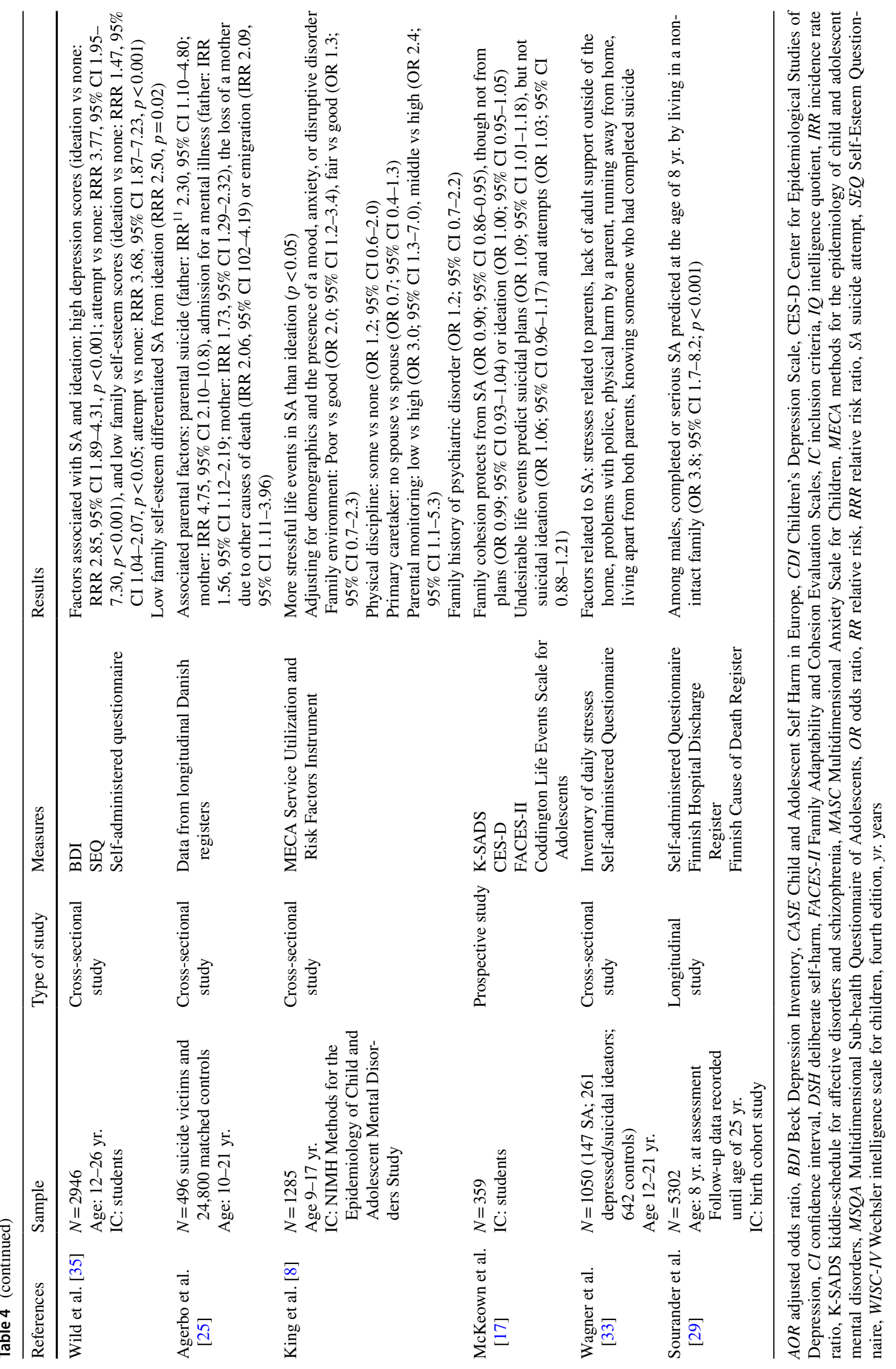




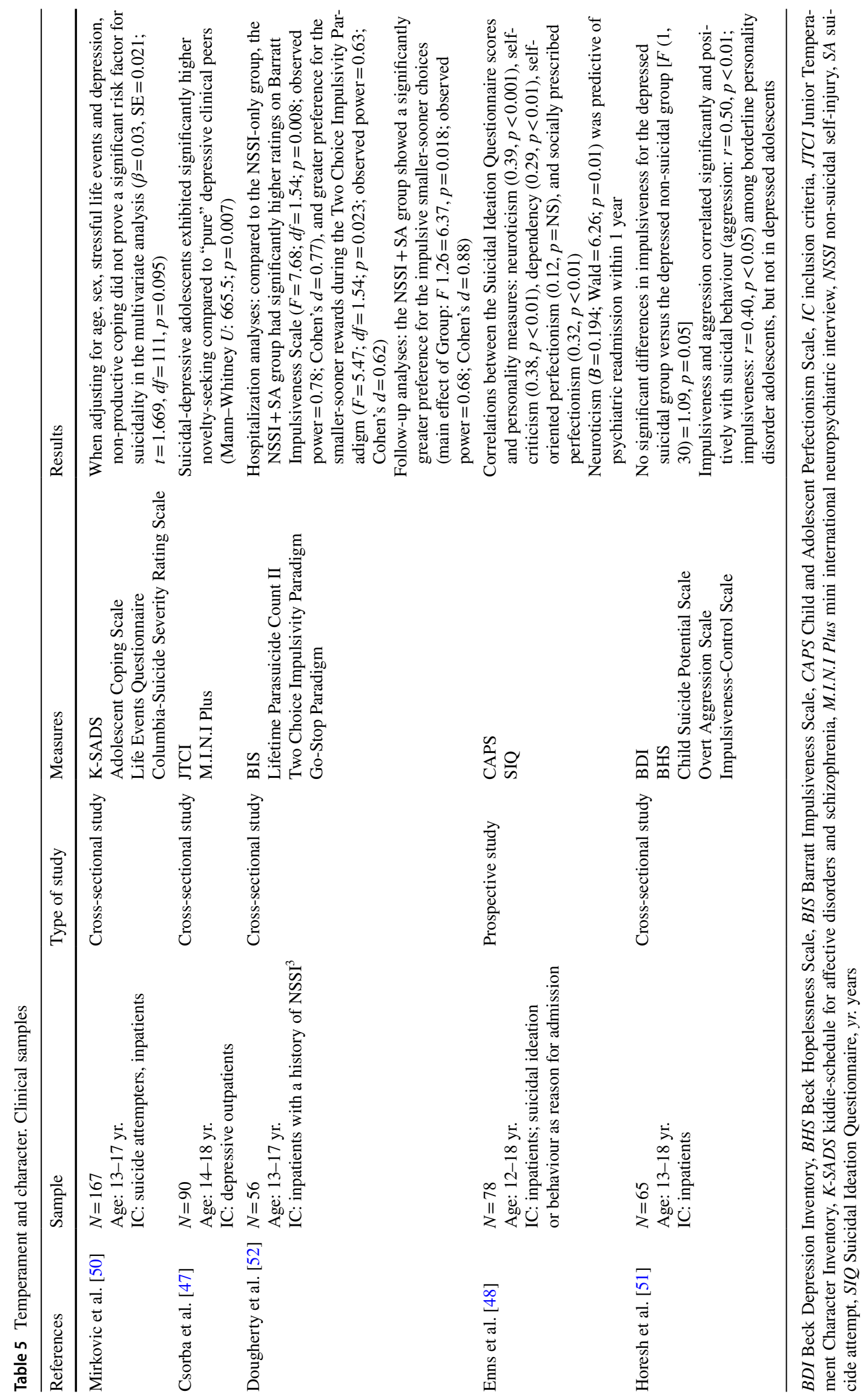


Table 6 Temperament and character. Non-clinical samples

\begin{tabular}{|c|c|c|c|c|}
\hline References & Sample & Type of study & Measures & Results \\
\hline O'Connor et al. [20] & $\begin{array}{l}N=2008 \\
\text { Age: } 15-16 \mathrm{yr} . \\
\text { IC: pupils }\end{array}$ & Cross-sectional study & $\begin{array}{l}\text { Version of the CASE ques- } \\
\text { tionnaire }\end{array}$ & $\begin{array}{l}\text { Optimism protects girls from } \\
\text { self-harm (OR 0.93; } 95 \% \mathrm{CI}^{4} \\
0.88-0.97 ; p<0.005)\end{array}$ \\
\hline $\begin{array}{l}\text { Chabrol and Saint- } \\
\text { Martin [46] }\end{array}$ & $\begin{array}{l}N=312 \\
\text { Age: } 14-18 \text { yr. } \\
\text { IC: students }\end{array}$ & Cross-sectional study & $\begin{array}{l}\text { CES-D } \\
\text { Youth Psychopathic traits } \\
\text { Inventory }\end{array}$ & $\begin{array}{l}\text { Affective component of psycho- } \\
\text { pathic traits is an independent } \\
\text { predictor of suicidal ideation } \\
(\beta=0.17, t=3.04, p=0.002)\end{array}$ \\
\hline Martin et al. [37] & $\begin{array}{l}N=2603 \\
\text { Age: } 13 \text { yr. (time 1), } 14 \text { yr. } \\
\text { (time } 2 \text { ), and } 15 \text { yr. (time } \\
\text { 3). } \\
\text { IC: students }\end{array}$ & Prospective study & $\begin{array}{l}\text { A single-item measure of } \\
\text { perceived academic per- } \\
\text { formance } \\
\text { Rosenberg's Self-esteem } \\
\text { Scale } \\
\text { Nowicki-Strickland Locus } \\
\text { of Control Scale for } \\
\text { Children }\end{array}$ & $\begin{array}{l}\text { Low self-esteem associated with } \\
\text { suicide thoughts (OR between } \\
2.39 \text { and } 3.48 \text { ), plans (OR } \\
\text { between } 2.76 \text { and } 3.55) \text {, threats } \\
\text { (OR between } 2.51 \text { and } 3.72 \text { ), } \\
\text { deliberate self-injury (OR } \\
\text { between } 1.99 \text { and } 2.58 \text { ), and SA }{ }^{5} \\
\text { (OR between } 2.26 \text { and } 4.30) \text {. } \\
\text { External attributional style associ- } \\
\text { ated with suicide thoughts (OR } \\
\text { between } 1.86 \text { and } 2.39 \text { ), plans } \\
\text { (OR between } 1.91 \text { and } 2.74), \\
\text { threats (OR between } 1.72 \text { and } \\
1.95 \text { ), deliberate self-injury (OR } \\
\text { between } 2.06 \text { and } 3.34), \text { ad SA } \\
\text { (OR between } 1.79 \text { and } 2.90)\end{array}$ \\
\hline Barber [49] & $\begin{array}{l}\text { Study I } \\
N=2619 \\
\text { Age: } 11-20 \text { yr. IC: students } \\
\text { Study II } \\
N=2111 \\
\text { Age: } 12-17 \text { yr. IC: students }\end{array}$ & Cross-sectional study & $\begin{array}{l}\text { Study I: } \\
\text { Structured Question- } \\
\text { naire. Youth suicide rate } \\
\text { obtained from 1994 World } \\
\text { Health Organization } \\
\text { statistics } \\
\text { Study II: } \\
\text { Self-administered question- } \\
\text { naires }\end{array}$ & $\begin{array}{l}\text { Study I: correlations between } \\
\text { adjustment and suicide: } \\
\text { Males: total adjustment } \\
r(7)=0.74, p<0.05 \text {; self-esteem } \\
r(7)=0.87, p=0.01 \text {; school } \\
\text { adjustment } r(7)=0.81, p<0.05 \text {; } \\
\text { social adjustment NS } \\
\text { Females: all adjustment analyses } \\
\text { NS } \\
\text { Study II: in males, suicidality was } \\
\text { significantly associated with } \\
\text { the interaction social compari- } \\
\text { son } \times \text { depressed affect }(t=9.4, \\
p<0.001) \text {, social comparison } \\
(t=-4.5, p<0.001) \text { and with } \\
\text { the interaction social com- } \\
\text { parison } \times \text { self-esteem }(t=9.5, \\
p<0.001) \text {. Among females, } \\
\text { suicidality was significantly } \\
\text { associated with depressed } \\
\text { affect }(t=4.3, p<0.001), \text { the } \\
\text { interaction social compari- } \\
\text { son } \times \text { depressed affect }(t=5.0, \\
p<0.001), \text { self-esteem }(t=-2.2 \text {, } \\
p<0.05), \text { social comparison } \\
(t=-3.7, p<0.001), \text { and inter- } \\
\text { action social comparison } \times \text { self- } \\
\text { esteem }(t=5.2, p<0.001)\end{array}$ \\
\hline
\end{tabular}

CASE Child and Adolescent Self Harm in Europe, CES-D Center for Epidemiological Studies of Depression, $C I$ confidence interval, IC inclusion criteria, $O R$ odds ratio, $S A$ suicide attempt, $y r$. years

depressive disorder increases the risk of suicide attempts [4]. Nevertheless, mood disorders do not explain all suicidal ideation and behaviours [5], and important distinctions must exist between depressed adolescents who have experienced suicidal ideation but have never attempted suicide and those who have done so. The evidence clearly highlights the complexity of suicidality and points towards an interaction of factors contributing to suicidal behaviour. Previous history 
Table 7 Studies investigating risk factors for suicidality among children and adolescents by type of self-injurious thought and/or behaviour

\begin{tabular}{|c|c|c|c|c|c|}
\hline Variable & Suicide attempt & Suicidal behaviour & Suicidal ideation/plan & $\begin{array}{l}\text { Non- } \\
\text { suicidal } \\
\text { self-injury }\end{array}$ & $\begin{array}{l}\text { Self- } \\
\text { injurious } \\
\text { behaviour }\end{array}$ \\
\hline \multicolumn{6}{|l|}{ Clinical variables } \\
\hline Depression & {$[4,8,9,11-14,29,35]$} & {$[9,12]$} & {$[5,9,12-14,35]$} & & {$[12]$} \\
\hline Previous suicide attempt & {$[15,16]$} & & {$[17]$} & & \\
\hline Previous suicidal ideation & {$[18]$} & {$[12,18]$} & {$[18]$} & {$[18]$} & {$[12,18]$} \\
\hline Alcohol and substance use & {$[21]$} & {$[2,4,5,8,11,13,18-20,22]$} & {$[5]$} & & {$[23]$} \\
\hline Eating disorders & & {$[26]$} & {$[26]$} & & {$[26]$} \\
\hline Psychiatric disorders & {$[4,8,27]$} & & {$[30]$} & & {$[20]$} \\
\hline Hospitalization & [16] & & & & \\
\hline Sleep disturbances & & & & & {$[20]$} \\
\hline \multicolumn{6}{|l|}{ Adverse life events } \\
\hline Family conflicts & {$[8,12,17,18]$} & {$[12,18]$} & {$[8,12,17,18,34]$} & & {$[12,18]$} \\
\hline Interpersonal and legal problems & {$[12]$} & {$[12]$} & {$[12]$} & & {$[12]$} \\
\hline Change of residence & {$[42]$} & & & & \\
\hline Romantic break-up & {$[11]$} & & & & \\
\hline Exposure to suicidal behaviour & {$[11,29]$} & & & & \\
\hline Bullying & & [39] & {$[32,41,44]$} & & {$[40]$} \\
\hline Abuse & & & {$[45]$} & & {$[43]$} \\
\hline Sexual orientation & & & & & [43] \\
\hline Academic performance & & & {$[37]$} & & \\
\hline \multicolumn{6}{|l|}{ Temperament and character } \\
\hline Novelty seeking & [47] & & & & \\
\hline Impulsiveness & {$[4,52]$} & {$[52]$} & {$[17]$} & {$[52]$} & \\
\hline $\begin{array}{l}\text { Neuroticism, pessimism, perfec- } \\
\text { tionism, dependence }\end{array}$ & & & [48] & & {$[20]$} \\
\hline Low self esteem & [37] & & {$[37]$} & & [37] \\
\hline External attributional style & [37] & & {$[37]$} & & [37] \\
\hline
\end{tabular}

of suicide attempts can identify a population at risk $[15,17]$, as does the concurrence of different disorders [4].

However, predicting which adolescents are likely to repeat their suicidal behaviour is still an area that needs further development. The natural history of suicidal behaviour among children and adolescents is not completely delineated. Clearly, more information is needed to understand the complex relationship between risk factors for suicidality and to be able to establish prevention strategies for suicidality in children and adolescents. Prospective studies with adequate sample sizes are needed to investigate these multiple variables of risk concurrently and over time.

Drug and/or alcohol misuse may also increase the risk for suicide attempt $[8,11,18]$. Acute intoxication may even trigger the suicidal act in vulnerable individuals by increasing impulsiveness, enhancing depressive thoughts and suicidal ideation, limiting cognitive functions and ability to see alternative coping strategies, and reducing barriers to self-inflicted harm [53]. In this vein, drug and/or alcohol misuse may act as proximal but also distal risk factors for suicidality and also may mediate or moderate the influence of other risk factors on suicidality [54]. Moreover, common neurobiological vulnerability has been described in depression, impulsivity and drug and/or alcohol use disorders such as a greater serotonergic impairment [53], which may help explain their frequent co-association and also their relationship with suicidal behaviour, a violent behaviour associated with disturbances in the serotonergic system [53].

In addition, vulnerability to suicidal behaviour may be, at least to some degree, mediated by some personality traits, such as neuroticism and impulsivity [17, 20, 48, 51, 52]. The association of poor emotional regulation strategies and behavioural impulsivity with suicidal behaviour leads to consider the existence of affective regulation vulnerability among children and adolescents at risk for suicidality.

Stressful life events may act as precipitating factors for suicidal behaviour. Our review identified several circumstances, such as family problems and peer conflicts that may exceed the coping strategies of some adolescents [8, $18,20,25,29,33-36]$. Nevertheless, it is important to note that some investigations suggest that it is the accumulation of stressful life events, and not the presence of one isolated 
stressful life event that appears to be related to later suicidal behaviours [55]. However, as not all children exposed to stressful life events develop suicidal behaviours, some authors state that suicidality is not simply a logical response to extreme stress [54], which in turn leads to the hypothesis of a stress diathesis model of suicidal behaviour [56]. Thus, from a suicidal behaviour prevention standpoint, further investigation is needed to clarify the relationship between stressful life events and suicidality in the paediatric population.

\section{Limitations}

The conclusions that can be made regarding the strength of association between the risk factors presented in this review and suicidality are limited due to the relatively small amount of prospective studies that have been conducted to date [4, $5,12,15,17,18,22,27,29,31,37,39,40,43,48]$. In addition, the majority of clinical studies used/studied/observed small populations. Publication bias is likely to be present as studies reporting no association between a risk factor and suicidal behaviour may not have been published. Suicidality was not measured by means of the same instrument across all the studies. Similarly, different instruments were used to measure psychopathology or to determine other psychosocial variables, which is another limitation. The age range of participants and sociodemographic variables differs between the different studies making direct comparisons and summaries across studies difficult/troublesome.

In conclusion, this review has pulled together relevant scientific literature addressing psychosocial risk factors for suicidality in children and adolescents. It suggests that various components and factors may contribute to the risk/ development of suicidality and suicidal behaviour in a young person, e.g. impulsivity, mood disorder, substance abuse, history of self-injury, and family and/or peer conflicts, to be considered as a cumulative/interactive process. The identifications of paediatric patients at high risk for suicidality and elements of resilience will improve preventative measure in targeted subgroups.

Acknowledgements The members of the STOP Consortium are: Alastair Sutcliffe. University College London, Institute of Child Health, London, United Kingdom. Sarah Curran. St George's University Hospital, London, UK. Laura Selema. Institute of Psychiatry, Psychology and Neurosciences (IoPPN), King's College London, London, UK. Robert Flanagan. Institute of Psychiatry, Psychology and Neurosciences (IoPPN), King's College London, London, UK. Ian Craig. Institute of Psychiatry, Psychology and Neurosciences (IoPPN), King's College London, London, UK. Nathan Parnell. Institute of Psychiatry, Psychology and Neurosciences (IoPPN), King's College London, London, UK. Keren Yeboah. Institute of Psychiatry, Psychology and Neurosciences (IoPPN), King's College London, London, UK. Regina Sala. Institute of Psychiatry, Psychology and Neuroscience (IoPPN), King's College London, London, UK. Jatinder Singh. Institute of Psychiatry, Psychology and Neuroscience (IoPPN), King's College London, London, UK.
Federico Fiori. Institute of Psychiatry, Psychology and Neuroscience (IoPPN), King's College London, London, UK. Centre for Interventional Paediatric Psychopharmacology and Rare Diseases (CIPPRD), South London and Maudsley NHS Foundation Trust, London, UK. HealthTracker Ltd, Gillingham, UK. Florence Pupier. CHRU Montpellier; Hôpital Saint Eloi, Médecine Psychologique de l'Enfant et de l'Adolescent, Montpellier, France. Loes Vinkenvleugel. Radboud University Medical Centre, Nijmegen, The Netherlands. Jeffrey Glennon. Radboud University Medical Centre., Nijmegen, The Netherlands. Mireille Bakker. Radboud University Medical Centre, Nijmegen, The Netherlands. Cora Drent. University of Groningen, University Medical Center Groningen, Department of Child and Adolescent Psychiatry, The Netherlands. Elly Bloem. University of Groningen, University Medical Center Groningen, Department of Child and Adolescent Psychiatry, The Netherlands. Mark-Peter Steenhuis. University of Groningen, University Medical Center Groningen, Department of Child and Adolescent Psychiatry, The Netherlands. Ruth Berg. Central Institute of Mental Health, Mannheim, Germany. Alexander Häge. Central Institute of Mental Health, Mannheim, Germany. Mahmud Ben Dau. Central Institute of Mental Health, Mannheim, Germany. Konstantin Mechler. Central Institute of Mental Health, Mannheim, Germany. Sylke Rauscher. Central Institute of Mental Health, Mannheim, Germany. Sonja Aslan. University of Ulm, Ulm, Germany. Simon Schlanser. University of Ulm, Ulm, Germany. Ferdinand Keller. University of Ulm, Ulm, Germany. Alexander Schneider. University of Ulm, Ulm, Germany. Paul Plener. University of Ulm, Ulm, Germany. Jörg M. Fegert. University of Ulm, Ulm, Germany. Jacqui Paton. University of Dundee, UK. Murray, Macey. University College London, UK. Noha Iessa. World Health Organization, London, UK. Kolozsvari, Alfred. HealthTracker Ltd, Gillingham, UK. Furse, Helen. HealthTracker Ltd, Gillingham, UK. Penkov, Nick. HealthTracker Ltd, Gillingham, UK. Claire Baillon. Assistance Publique-Hopitaux de Paris: Robert Debré Hospital, Paris, France. Hugo Peyre. Assistance Publique-Hopitaux de Paris:Robert Debré Hospital, Paris, France. David Cohen. Assistance Publique-Hopitaux de Paris: Groupe Hospitalier Pitié-Salpêtrière, Paris, France. Olivier Bonnot. Assistance Publique-Hopitaux de Paris: Groupe Hospitalier Pitié-Salpêtrière, Paris, France. Julie Brunelle. Assistance Publique-Hopitaux de Paris: Groupe Hospitalier Pitié-Salpêtrière, Paris, France. Nathalie Franc. CHRU Montpellier; Hôpital Saint Eloi, Médecine Psychologique de l'Enfant et de l'Adolescent, France. Pierre Raysse. CHRU Montpellier; Hôpital Saint Eloi, Médecine Psychologique de l'Enfant et de l'Adolescent, France. Véronique Humbertclaude. CHRU Montpellier; Hôpital Saint Eloi, Médecine Psychologique de l'Enfant et de l'Adolescent, France. Alberto Rodriguez-Quiroga. Child and Adolescent Psychiatry Department, Hospital General Universitario Gregorio Marañón, CIBERSAM, Instituto de Investigación Sanitaria Gregorio Marañón (IiSGM), School of Medicine, Universidad Complutense, Madrid, Spain. Covadonga Martínez Díaz-Caneja. Child and Adolescent Psychiatry Department, Hospital General Universitario Gregorio Marañón, CIBERSAM, Instituto de Investigación Sanitaria Gregorio Marañón (IiSGM), School of Medicine, Universidad Complutense, Madrid, Spain. Ana Espliego. CIBERSAM, Madrid, Spain. Jessica Merchán. CIBERSAM, Madrid, Spain. Cecilia Tapia. CIBERSAM, Madrid, Spain. Immaculada Baeza. Fundació Clínic per la Recerca Biomèdica, Barcelona, Spain. Soledad Romero. Fundació Clínic per 1a Recerca Biomèdica, Barcelona, Spain. Amalia La Fuente. University of Barcelona, Spain. Ana Ortiz. Fundació Clínic per la Recerca Biomèdica, Barcelona, Spain. Manuela Pintor. Cagliari University Hospital, Cagliari, Italy. Franca Ligas. University of Cagliari, Cagliari, Italy. Francesca Micol Cera, University of Cagliari, Cagliari, Italy. Roberta Frongia, Cagliari University Hospital, Cagliari, Italy. Bruno Falissard. Univ. Paris-Sud, INSERM U669, AP-HP, Paris, France. Ameli Schwalber. Concentris, Germany. Juliane Dittrich. Concentris, Germany. Andrea Wohner. Concentris, Germany. Katrin Zimmermann. 
Concentris, Germany. Andrea Schwalber. Concentris, Germany. Katherine Aitchison. University of Alberta, Calgary, Canada.

Funding This research was funded by the European Community's Seventh Framework Programme (FP7/2007-2013) under Grant agreement no. 261411. The research was also supported by the Spanish Ministry of Economy and Competitiveness, Instituto de Salud Carlos III, cofinanced by ERDF Funds from the European Commission, "A way of making Europe", CIBERSAM, Madrid Regional Government (S2010/ BMD-2422 AGES) and European Union Structural Funds, Fundación Alicia Koplowitz and Fundación Mutua Madrileña.

\section{Compliance with ethical standards}

Conflict of interest Professor Paramala Santosh, is the CEO, Director and stockholder in HealthTracker Ltd. Dr. K. Lievesley is a Project Manager employed at HealthTracker Ltd. Dr. Dittmann has received compensation for serving as consultant or speaker, or he or the institution he works for have received research support or royalties from the organizations or companies indicated: EU (FP7 Programme), US National Institute of Mental Health (NIMH), German Federal Ministry of Health/Regulatory Agency (BMG/BfArM), German Federal Ministry of Education and Research (BMBF), German Research Foundation (DFG), Volkswagen Foundation; Boehringer Ingelheim, Ferring, Janssen-Cilag, Lilly, Lundbeck, Otsuka, Servier, Shire, Sunovion/ Takeda and Theravance. Dr. Dittmann owns Eli Lilly stock. Dr. Zuddas has been a consultant to or has received honoraria or grants from EU (FP7 Programme), Angelini, Lundbeck, Janssen, Roche, Servier, Shire, Takeda, Vifor. Prof. Coghill reports grants and personal fees from Shire, personal fees from Janssen-Cilag, personal fees from Lilly, grants and personal fees from Vifor, personal fees from Novartis, personal fees from Flynn Pharma, personal fees from Medice, personal fees from Oxford University Press, outside the submitted work. Dr. Arango has been a consultant to or has received honoraria or grants from Acadia, Abbot, AMGEN, AstraZeneca, Bristol-Myers Squibb, Janssen-Cilag, Lundbeck, Merck, Otsuka, Pfizer, Roche, Servier, Sumitomo-Dainippon Pharma, Shire, Takeda, Teva and Schering Plough. Dr Purper-Ouakil has been consultant for Shire, Boiron, Mensia and has received honoraria or travel grants from Shire, Otsuka, Medice, Jannssen-Cilag, Ardix. None of the other authors have any conflicts of interest or disclosures to declare. Part of this data has been included in an FP7 STOP Report to the European Union.

Informed consent Informed consent was obtained from all study participants.

Ethical approval The study was approved by the Research Ethic Committees (RECs)/Institutional Review Boards (IRBs) of all participating centres.

OpenAccess This article is distributed under the terms of the Creative Commons Attribution 4.0 International License (http://creativeco mmons.org/licenses/by/4.0/), which permits unrestricted use, distribution, and reproduction in any medium, provided you give appropriate credit to the original author(s) and the source, provide a link to the Creative Commons license, and indicate if changes were made.

\section{References}

1. World Health Organization (2002) World report on violence and health. WHO, Geneva
2. Prevention, C.f.D.C.a.; (2017) http://www.cdc.gov/violencepr evention/pub/youth_suicide.html. Accessed 12 Sept 2017

3. Parellada $\mathrm{M}$ et al (2008) Is attempted suicide different in adolescent and adults? Psychiatry Res 157(1-3):131-137

4. Goldston DB et al (2009) Psychiatric diagnoses as contemporaneous risk factors for suicide attempts among adolescents and young adults: developmental changes. J Consult Clin Psychol 77(2):281-290

5. Arria AM et al (2009) Suicide ideation among college students: a multivariate analysis. Arch Suicide Res 13(3):230-246

6. Birmaher B et al (2007) Practice parameter for the assessment and treatment of children and adolescents with depressive disorders. J Am Acad Child Adolesc Psychiatry 46(11):1503-1526

7. Moher D et al (2009) Preferred reporting items for systematic reviews and meta-analyses: the PRISMA statement. PLoS Med 6(7):e1000097

8. King RA et al (2001) Psychosocial and risk behavior correlates of youth suicide attempts and suicidal ideation. J Am Acad Child Adolesc Psychiatry 40(7):837-846

9. Spann M et al (2006) Suicide and African American teenagers: risk factors and coping mechanisms. Suicide Life Threat Behav 36(5):553-568

10. Vitiello B et al (2009) Depressive symptoms and clinical status during the Treatment of Adolescent Suicide Attempters (TASA) Study. J Am Acad Child Adolesc Psychiatry 48(10):997-1004

11. Asarnow JR et al (2008) Pediatric emergency department suicidal patients: two-site evaluation of suicide ideators, single attempters, and repeat attempters. J Am Acad Child Adolesc Psychiatry 47(8):958-966

12. Vitiello B et al (2009) Suicidal events in the Treatment for Adolescents with Depression Study (TADS). J Clin Psychiatry 70(5):741-747

13. Park HS, Koo HY, Schepp KG (2005) Predictors of suicidal ideation for adolescents by gender. Taehan Kanho Hakhoe Chi 35(8):1433-1442

14. Beautrais AL (2003) Suicide and serious suicide attempts in youth: a multiple-group comparison study. Am J Psychiatry 160(6):1093-1099

15. Hulten A et al (2001) Repetition of attempted suicide among teenagers in Europe: frequency, timing and risk factors. Eur Child Adolesc Psychiatry 10(3):161-169

16. Goldstein TR et al (2005) History of suicide attempts in pediatric bipolar disorder: factors associated with increased risk. Bipolar Disord 7(6):525-535

17. McKeown RE et al (1998) Incidence and predictors of suicidal behaviors in a longitudinal sample of young adolescents. J Am Acad Child Adolesc Psychiatry 37(6):612-619

18. Brent DA et al (2009) Predictors of spontaneous and systematically assessed suicidal adverse events in the treatment of SSRIresistant depression in adolescents (TORDIA) study. Am J Psychiatry 166(4):418-426

19. Rossow I et al (2007) Cross-national comparisons of the association between alcohol consumption and deliberate self-harm in adolescents. Suicide Life Threat Behav 37(6):605-615

20. O'Connor RC et al (2009) Self-harm in adolescents: self-report survey in schools in Scotland. Br J Psychiatry 194(1):68-72

21. Weiner DA, Abraham ME, Lyons J (2001) Clinical characteristics of youths with substance use problems and implications for residential treatment. Psychiatr Serv 52(6):793-799

22. Wilcox HC, Anthony JC (2004) The development of suicide ideation and attempts: an epidemiologic study of first graders followed into young adulthood. Drug Alcohol Depend 76(Suppl):S53-S67

23. Black K, Asbridge M, Lea S (2009) An overview of injuries to adolescents and young adults related to substance use: data from Canadian emergency departments. CJEM 11(4):330-336 
24. Fischer S, le Grange D (2007) Comorbidity and high-risk behaviors in treatment-seeking adolescents with bulimia nervosa. Int $\mathrm{J}$ Eat Disord 40(8):751-753

25. Agerbo E, Nordentoft M, Mortensen PB (2002) Familial, psychiatric, and socioeconomic risk factors for suicide in young people: nested case-control study. BMJ 325(7355):74

26. Buhren $\mathrm{K}$ et al (2014) Comorbid psychiatric disorders in female adolescents with first-onset anorexia nervosa. Eur Eat Disord Rev 22(1):39-44

27. Kelleher I et al (2013) Psychotic symptoms and population risk for suicide attempt: a prospective cohort study. JAMA Psychiatry 70(9):940-948

28. Singareddy R et al (2013) Subjective and objective sleep and selfharm behaviors in young children: a general population study. Psychiatry Res 209(3):549-553

29. Sourander A et al (2009) Childhood predictors of completed and severe suicide attempts: findings from the Finnish 1981 Birth Cohort Study. Arch Gen Psychiatry 66(4):398-406

30. Storch EA et al (2013) The phenomenology and clinical correlates of suicidal thoughts and behaviors in youth with autism spectrum disorders. J Autism Dev Disord 43(10):2450-2459

31. Czyz EK, Berona J, King CA (2016) Rehospitalization of suicidal adolescents in relation to course of suicidal ideation and future suicide attempts. Psychiatr Serv 67(3):332-338

32. Pan SW, Spittal PM (2013) Health effects of perceived racial and religious bullying among urban adolescents in China: a crosssectional national study. Glob Public Health 8(6):685-697

33. Wagner BM, Cole RE, Schwartzman P (1995) Psychosocial correlates of suicide attempts among junior and senior high school youth. Suicide Life Threat Behav 25(3):358-372

34. Kerr DC, Preuss LJ, King CA (2006) Suicidal adolescents' social support from family and peers: gender-specific associations with psychopathology. J Abnorm Child Psychol 34(1):103-114

35. Wild LG, Flisher AJ, Lombard C (2004) Suicidal ideation and attempts in adolescents: associations with depression and six domains of self-esteem. J Adolesc 27(6):611-624

36. Bruffaerts $\mathrm{R}$ et al (2010) Childhood adversities as risk factors for onset and persistence of suicidal behaviour. Br J Psychiatry 197(1):20-27

37. Martin G et al (2005) Perceived academic performance, selfesteem and locus of control as indicators of need for assessment of adolescent suicide risk: implications for teachers. J Adolesc 28(1):75-87

38. Roxborough HM et al (2012) Perfectionistic self-presentation, socially prescribed perfectionism, and suicide in youth: a test of the perfectionism social disconnection model. Suicide Life Threat Behav 42(2):217-233

39. Klomek AB et al (2009) Childhood bullying behaviors as a risk for suicide attempts and completed suicides: a population-based birth cohort study. J Am Acad Child Adolesc Psychiatry 48(3):254-261
40. Fisher HL et al (2012) Bullying victimisation and risk of self harm in early adolescence: longitudinal cohort study. BMJ 344:e2683

41. Herba CM et al (2008) Victimization and suicide ideation in the TRAILS study: specific vulnerabilities of victims. J Child Psychol Psychiatry 49(8):867-876

42. Qin P, Mortensen PB, Pedersen CB (2009) Frequent change of residence and risk of attempted and completed suicide among children and adolescents. Arch Gen Psychiatry 66(6):628-632

43. O'Connor RC, Rasmussen S, Hawton K (2009) Predicting deliberate self-harm in adolescents: a six month prospective study. Suicide Life Threat Behav 39(4):364-375

44. Wan Y et al (2015) Impact of childhood abuse on the risk of nonsuicidal self-injury in mainland Chinese adolescents. PLoS One 10(6): $\mathrm{e} 0131239$

45. Kiss L et al (2015) Exploitation, Violence, and suicide risk among child and adolescent survivors of human trafficking in the greater Mekong subregion. JAMA Pediatr 169(9):e152278

46. Chabrol H, Saint-Martin C (2009) Psychopathic traits and suicidal ideation in high-school students. Arch Suicide Res 13(1):64-73

47. Csorba J et al (2010) Novelty seeking: difference between suicidal and non-suicidal Hungarian adolescent outpatients suffering from depression. J Affect Disord 120(1-3):217-220

48. Enns MW, Cox BJ, Inayatulla M (2003) Personality predictors of outcome for adolescents hospitalized for suicidal ideation. J Am Acad Child Adolesc Psychiatry 42(6):720-727

49. Barber JG (2001) Relative misery and youth suicide. Aust N Z J Psychiatry 35(1):49-57

50. Mirkovic B et al (2015) Coping skills among adolescent suicide attempters: results of a multisite study. Can J Psychiatry 60(2 Suppl 1):S37-S45

51. Horesh $\mathrm{N}$ et al (2003) Comparison of the suicidal behavior of adolescent inpatients with borderline personality disorder and major depression. J Nerv Ment Dis 191(9):582-588

52. Dougherty DM et al (2009) Impulsivity and clinical symptoms among adolescents with non-suicidal self-injury with or without attempted suicide. Psychiatry Res 169(1):22-27

53. Sher L (2006) Alcohol and suicide: neurobiological and clinical aspects. Sci World J 6:700-706

54. Sher L (2006) Risk and protective factors for suicide in patients with alcoholism. Sci World J 6:1405-1411

55. McFeeters D et al (2015) Patterns of stressful life events: distinguishing suicide ideators from suicide attempters. J Affect Disord 175:192-198

56. Brodsky BS (2016) Early childhood environment and genetic interactions: the diathesis for suicidal behavior. Curr Psychiatry Rep 9:86 


\section{Affiliations}

\section{J. J. Carballo ${ }^{1}$. C. Llorente ${ }^{1} \cdot$ L. Kehrmann ${ }^{1} \cdot$ I. Flamarique $^{2} \cdot$ A. Zuddas $^{3}$ - D. Purper-Ouakil ${ }^{4}$ P. J. Hoekstra ${ }^{5}$. D. Coghill $6,7,8,9 \cdot$ U. M. E. Schulze ${ }^{10} \cdot$ R. W. Dittmann ${ }^{11} \cdot$ J. K. Buitelaar ${ }^{12} \cdot$ J. Castro-Fornieles ${ }^{2,13,14} \cdot$ K. Lievesley $^{15,16,17}$. Paramala Santosh ${ }^{15,16,17 \text { (i) }}$. C. Arango ${ }^{1}$ on behalf of the STOP Consortium}

1 Child and Adolescent Psychiatry Department, Hospital General Universitario Gregorio Marañón, CIBERSAM, Instituto de Investigación Sanitaria Gregorio Marañón (IiSGM), School of Medicine, Universidad Complutense, Madrid, Spain

2 Child and Adolescent Psychiatry and Psychology Department, 2014SGR489, Institute Clinic of Neurosciences, Hospital Clinic of Barcelona, CIBERSAM, Barcelona, Spain

3 Child and Adolescent Neuropsychiatry Unit, Department of Biomedical Sciences, University of Cagliari, and "A. Cao" Paediatric Hospital, “G. Brotzu” Hospital Trust, Cagliari University Hospital, Cagliari, Italy

4 CHRU Montpellier, Hôpital Saint Eloi, Médecine Psychologique de 1'Enfant et de l'Adolescent, Montpellier, France

5 Department of Child and Adolescent Psychiatry, University of Groningen, University Medical Center Groningen, Groningen, The Netherlands

6 Department of Paediatrics, School of Medicine, Dentistry and Health Sciences, University of Melbourne, Melbourne, Australia

7 Department of Psychiatry, School of Medicine, Dentistry and Health Sciences, University of Melbourne, Melbourne, Australia

8 Murdoch Children's Research Institute, Melbourne, Australia
9 Division of Neuroscience, School of Medicine, University of Dundee, Dundee, UK

10 Department of Child and Adolescent Psychiatry/Psychotherapy, University of Ulm, Ulm, Germany

11 Paediatric Psychopharmacology, Department of Child and Adolescent Psychiatry, Central Institute of Mental Health (CIMH), Medical Faculty Mannheim, University of Heidelberg, Mannheim, Germany

12 Department of Cognitive Neuroscience, Donders Institute for Brain, Cognition and Behaviour, Radboud University Medical Centre, and Karakter Child and Adolescent Psychiatry University Centre, Nijmegen, The Netherlands

13 Centro de Investigación Biomédica en Red de Salud Mental, CIBERSAM, Barcelona, Spain

14 Department of Psychiatry and Clinical Psychology, University of Barcelona, Barcelona, Spain

15 Department of Child and Adolescent Psychiatry, Institute of Psychology, Psychiatry and Neuroscience, King's College London, London, UK

16 Centre for Interventional Paediatric Psychopharmacology and Rare Diseases (CIPPRD), South London and Maudsley NHS Foundation Trust, London, UK

17 HealthTracker Ltd, Gillingham, Kent, UK 